\title{
Thermal Calculation of Ground Contact Structures: New Methods Based on Parametrized Transient Finite Element Thermal Modeling
}

\author{
B. NAGY* \\ Budapest University of Technology and Economics, Faculty of Civil Engineering, \\ Department of Construction Materials and Technologies, Budapest, Hungary
}

\begin{abstract}
The heat loss at ground contact structures is taken into consideration in building heat loss calculations. However, it implies uncertainties due to the physical properties of the soil as well as the building structure. In this paper, new methods are introduced for calculating the heat loss at ground contact structures. Firstly, it examines the presently used and general calculation methods and their shortcomings. Then a simple-to-use method based on thousands of results of parametrized transient finite element thermal models is shown. In this research, the calculations take the middle-eastern European climate conditions, geothermal gradient and soil properties as well as the relevant harmonized EU standards into account. The equivalent linear heat transfer coefficients, which in this method also contain the effects of thermal bridges, occurring in various conditions are summarized in a table and can be calculated by new formulae also shown in the paper using condition-dependent constants, the ground floor's heat transfer coefficient and the length between the floor and ground level.
\end{abstract}

DOI: 10.12693/APhysPolA.128.B-164

PACS: 44.05. $+\mathrm{e}, 44.10 .+\mathrm{i}$

\section{Introduction}

During heat transfer calculations the first law of thermodynamics, i.e. the law of conservation of energy, is applied to describe heat transport processes. In building physical modeling the starting equation is usually the differential equation of heat conduction. In modeling some components can be simplified according to real situations. In some cases, steady-state calculations decrease the accuracy significantly. In case of structures that contact with materials having considerable heat capacity, the greater heat capacity and thermal conductivity of solids influences the thermal behavior significantly. This phenomenon is neglected by a steady-state solution. For a building envelope, where the air at both sides has low heat capacity, and if the structure does not have significant thermal storage capability as well, the heat conduction differential equation for the whole heating season can be approximated by a stationary model indeed; results do not differ significantly, the heat losses are almost symmetrical at the heating period from Oct. 15th to Apr. 15th (see Fig. 1, external wall and plinth and basement wall). However, in case of ground contact structures, e.g. ground floor or basement walls, the heat stored in the soil and the geothermal gradient of the Earth have a significant effect on heat losses in heating seasons. At a floor structure the effects depending on the external temperature will delay, therefore heat losses cannot be approached by steady-state calculations in heating seasons (see Fig. 1, floor heat loss). These

*e-mail: nagy.balazs@epito.bme.hu phenomena can be investigated; it is possible to analyze a transient process by using numerical methods.

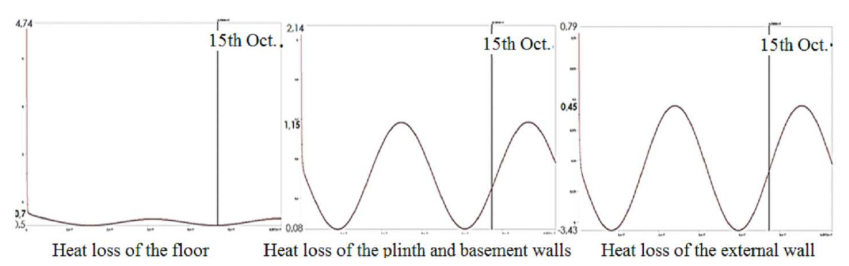

Fig. 1. Heat losses of heated basement's structures from transient simulation.

\section{Differential equation} of transient heat conduction to solve

In this paper the thermal simulations are limited to transient calculations of certain details of isotropic solids. The system of equations to solve is the following:

$$
\nabla(\lambda \nabla T)+Q=C_{p} \rho \frac{\partial T}{\partial t},
$$

where $\nabla$ is vectorial differential operator, $\lambda$ is thermal conductivity, $T$ is absolute temperature, $Q$ is internal heat generation, $C_{p}$ is specific heat capacity at constant pressure, $\rho$ is density, $t$ is time. To solve the differential equations for ground contact structures, the following procedures are available in international literature.

\subsection{Numerical solutions}

One of the first simulations for ground contact structures was based on explicit finite difference method, during which heat and moisture transport processes were studied in experimental underground shelters [1], and 
years later, results of multi-dimensional computer simulations were checked and verified by large model experiments [2]. In Hungary, FDM transient simulations are used in most cases [3]; however, it has number of constraints. The European Organization for Standardization has issued a standard in 1998, in which the heat flows and surface temperatures are regulated; the current version of this standard, being in force, is the EN ISO 10211: 2007.

\subsection{Analytical solutions}

In analytical solutions transient heat conduction equations are solved by simplified equations, after detailed studies and analyses. The first simplification is usually that the dynamic nature of the problem is neglected. One of these solutions was published in Canada at the end of the sixties [4]. The analytical methods provided solutions for two-dimensional cases with periodically changing boundary conditions, or even for heat losses of $3 \mathrm{D}$, rectangular floor structures in steady-state by the eighties [5]. The current standard, the EN ISO 13370: 2007 containing methods for calculating heat transfer processes in soils also applies analytical calculation procedures, that are based on publications of Swedish researchers in nineties [6].

\subsection{Semi-analytical solutions}

The semi-analytical solutions are a mix of analytical methods discussed above and the results of numerical calculations. An example of such procedures is a method [7], wherein the boundary value problem is described by a dynamic three-dimensional heat conduction equation applying the Green function.

\section{Material properties}

\begin{tabular}{l|c|c|c|} 
Structure and material, Standard & $\begin{array}{c}\text { Thickness } \\
{[\mathrm{m}]}\end{array}$ & $\begin{array}{c}\text { Thermal conductivity } \\
\lambda[\mathrm{W} / \mathrm{mK}]\end{array}$ & $\begin{array}{c}\text { Volumetric heat capacity } \\
\left.\mathrm{C}_{v}[\mathrm{M}] / \mathrm{m}^{3} \mathrm{~K}\right]\end{array}$ \\
\hline Floor, concrete - EN ISO 10456:2007 & 0,06 & 1,35 & 2,00 \\
\hline Floor, insulation, EPS - EN ISO 10456:2007 & parametrized & 0,04 & 0,03 \\
\hline Floor, reinforced concrete, 1\% steel - EN ISO 10456:2007 & 0,10 & 2,30 & 2,30 \\
\hline Soil, sand and gravel - EN ISO 13370:2007 & 15,00 & 2,00 & 2,00 \\
\hline Soil, clay and silt - EN ISO 13370:2007 & 15,00 & 1,50 & 3,00 \\
\hline External walls (PTH 44 K + 2 cm lime plaster) & 0,46 & 0,11 & 0,69 \\
\hline Plinth walls and basement walls (PTH 44 HS + 2 cm lime plaster) & 0,46 & 0,14 & 0,61 \\
\hline
\end{tabular}
Plinth walls and basement walls (PTH $44 \mathrm{HS}+2 \mathrm{~cm}$ lime plaster)

Simulation set

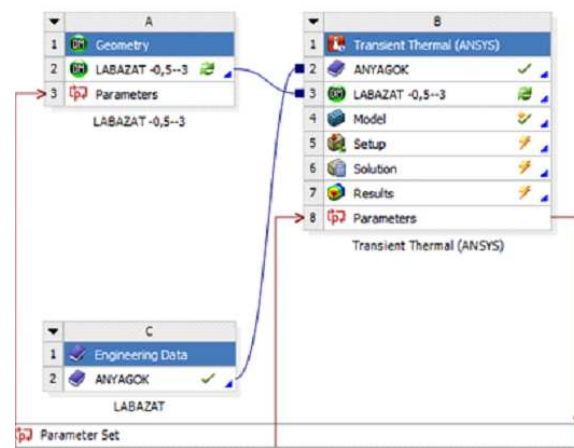

Modeled geometry, mesh, boundary conditions

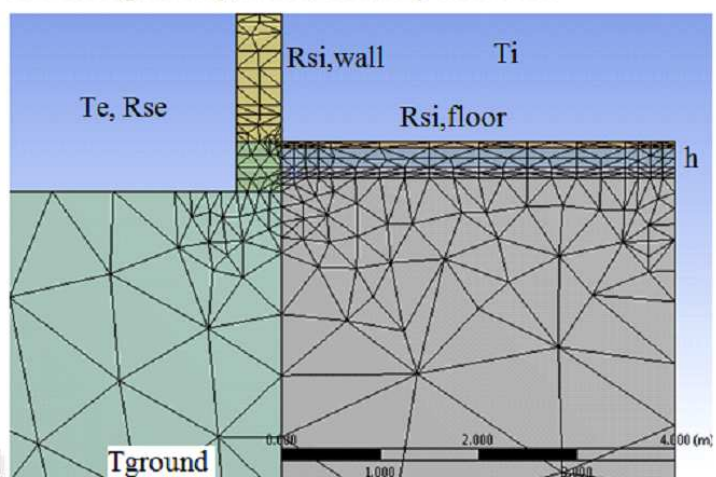

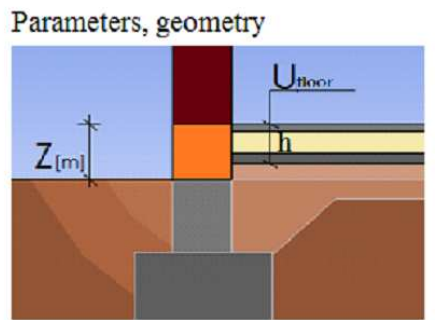

$h=\lambda_{\text {ins }} \cdot\left(\frac{1}{U_{\text {floor }}}-R_{s i}-\frac{d_{c}}{\lambda_{c}}-\frac{d_{r c}}{\lambda_{\text {re }}}\right)[m]$ $T e=T_{m}+T_{r} \cdot \cos \left(2,9+\frac{2 \cdot \pi \cdot X}{365}\right)\left[{ }^{\circ} \mathrm{C}\right]$ $T i=20^{\circ} \mathrm{C}$ $R_{s e}=\frac{1}{4+4 \cdot v+\varepsilon \cdot 4 \cdot \sigma \cdot(T e+273,15)^{3}}$ $R_{s i}=\frac{1}{h_{e i}+\varepsilon \cdot 4 \cdot \sigma \cdot(20+273,15)^{3}}$ $h_{e i}=$ walls: $5 \frac{\mathrm{W}}{\mathrm{m}^{2} \mathrm{~K}}$, floor $: 0,7 \frac{\mathrm{W}}{\mathrm{m}^{2} \mathrm{~K}}$ Tground $=9^{\circ} \mathrm{C}$ at $-15 \mathrm{~m}$

Fig. 2. Parameters and steps of FEA of transient heat conduction in ground contact structures.

\section{New calculation methods for ground contact structures}

During the research, a finite element software was applied, in which the calculations could be parameterized [8]. During the numerous simulation, the thickness of the thermal insulation of the floor $(h)$ varied as a function of heat transfer coefficients $\left(U_{\text {floor }}\right)$, that was investigated between $4 \mathrm{~W} /\left(\mathrm{m}^{2} \mathrm{~K}\right)$ and $0.1 \mathrm{~W} /\left(\mathrm{m}^{2} \mathrm{~K}\right)$. The position of the floor structure $(z)$ varied from $-3 \mathrm{~m}$ to $+3 \mathrm{~m}$ from the ground level. 3D model was created, therefore the geometrical effects could be studied. The length of the floor structure was $4 \mathrm{~m}$ uniformly, the footing was $0.5 \mathrm{~m}$ above ground level. The exterior wall was $1.5 \mathrm{~m}$ high from the footing. Basement walls, if applicable geometrically (negative $z$ ), were modeled from the bottom plane of the ground floor to the top plane of the soil. Each building material property as well as the boundary conditions were applied according to the current ISO standards. The outside temperature was approached by cosine-based function that was set to the daily average temperature of Hungary $(T e)$, while inside the building constant, required temperature $(T i)$ was assumed. The wind speed was approached as average $3 \mathrm{~m} / \mathrm{s}$ according to Hungarian meteorological services. The soil was considered down to $-15 \mathrm{~m}$ underground, where 9 degrees constant temperature $\left(T_{\text {ground }}\right)$ was assumed, that is typical in Central Europe. The transient finite element simulation parameters are presented in Fig. 2 . 


\section{Results}

After simulations of 3 consecutive years, the results of the last year were investigated in a table form. Table contains the equivalent linear thermal transmittances of a ground floor structure as a function of $U_{\text {floor }}$ and $z$, that can be determined by the following equation on the basis of the results obtained from the simulation:

$$
\psi_{t}=\frac{\sum\left(L_{3 D, i}[W] 10\right)}{1 m(T i-T e)} A_{\text {wall }} U_{\text {wall }} A_{\text {bwall }} U_{\text {bwall }},
$$

where $L_{3 D, i}$ is the daily average heat loss at the interior side of the structures considered at the standardized heating period. (It is multiplied by 10 , because the 3D model was simulated with $10 \mathrm{~cm}$ thickness for better computing performance.) $T_{i}-T_{e}$ is the average temperature difference, $U_{\text {wall }}$ and $U_{\text {bwall }}$ are the 1D calculated thermal transmittances of the wall and the plinth/basement walls, which was $0.24 \mathrm{~W} /\left(\mathrm{m}^{2} \mathrm{~K}\right)$ and $0.3 \mathrm{~W} /\left(\mathrm{m}^{2} \mathrm{~K}\right)$, respectively, according to Hungarian Regulation.

TABLE

Equivalent linear thermal transmittance $[\mathrm{W} /(\mathrm{mK})]$ of ground contact floor structures.

\begin{tabular}{c|c|c|c|c|c|c|c|c|c|c|c|c}
\hline \hline$U_{\text {floor }}$ & 4 & 2 & 1 & 0.75 & 0.5 & 0.4 & 0.3 & 0.25 & 0.2 & 0.15 & 0.1 \\
\cline { 2 - 10 }$z[\mathrm{~m}] \downarrow$ & \multicolumn{10}{|c}{$\left[\mathrm{W} / \mathrm{m}^{2} \mathrm{~K}\right]$} \\
\hline-3 & 0.92 & 0.82 & 0.64 & 0.57 & 0.47 & 0.41 & 0.34 & 0.30 & 0.25 & 0.20 & 0.13 \\
-2 & 1.03 & 0.91 & 0.70 & 0.63 & 0.52 & 0.46 & 0.38 & 0.34 & 0.29 & 0.23 & 0.16 \\
-1.5 & 1.10 & 0.96 & 0.75 & 0.67 & 0.55 & 0.49 & 0.41 & 0.36 & 0.31 & 0.25 & 0.18 \\
-1 & 1.20 & 1.06 & 0.80 & 0.72 & 0.59 & 0.52 & 0.44 & 0.39 & 0.33 & 0.27 & 0.20 \\
-0.75 & 1.25 & 1.10 & 0.84 & 0.75 & 0.61 & 0.54 & 0.46 & 0.41 & 0.35 & 0.28 & 0.21 \\
-0.5 & 1.32 & 1.16 & 0.88 & 0.78 & 0.64 & 0.57 & 0.48 & 0.43 & 0.37 & 0.30 & 0.22 \\
-0.25 & 1.40 & 1.22 & 0.93 & 0.82 & 0.67 & 0.60 & 0.50 & 0.45 & 0.38 & 0.31 & 0.24 \\
0 & 1.51 & 1.31 & 0.98 & 0.87 & 0.71 & 0.63 & 0.53 & 0.47 & 0.40 & 0.33 & 0.25 \\
0.25 & 1.65 & 1.42 & 1.05 & 0.93 & 0.77 & 0.68 & 0.55 & 0.49 & 0.42 & 0.35 & 0.26 \\
0.5 & 1.51 & 1.31 & 1.00 & 0.89 & 0.74 & 0.65 & 0.55 & 0.50 & 0.43 & 0.36 & 0.27 \\
0.75 & 1.41 & 1.23 & 0.96 & 0.85 & 0.72 & 0.64 & 0.53 & 0.47 & 0.42 & 0.34 & 0.26 \\
1 & 1.34 & 1.18 & 0.92 & 0.82 & 0.68 & 0.61 & 0.52 & 0.46 & 0.40 & 0.33 & 0.26 \\
1.5 & 1.23 & 1.09 & 0.87 & 0.78 & 0.65 & 0.58 & 0.50 & 0.44 & 0.39 & 0.32 & 0.25 \\
2 & 1.15 & 1.02 & 0.82 & 0.74 & 0.62 & 0.56 & 0.48 & 0.43 & 0.37 & 0.31 & 0.24 \\
3 & 1.04 & 0.92 & 0.76 & 0.68 & 0.58 & 0.52 & 0.45 & 0.41 & 0.36 & 0.30 & 0.23
\end{tabular}

Based on the results reported in Table, linear thermal transmittances of floor structures can also be calculated by the following equations:

$$
\begin{aligned}
& \text { for } z<0.25 \mathrm{~m} \\
& \qquad \begin{aligned}
\psi_{t} & =\left(0.0168 z^{2}+0.0947 z+0.3626\right) \ln \left(U_{\text {floor }}\right) \\
& +\left(0.0362 z^{2}+0.2294 z+0.997\right)
\end{aligned} \\
& \text { for } z \geq 0.25 \mathrm{~m} \\
& \quad \psi_{t}=0.3027 z^{-0.216} \ln \left(U_{\text {floor }}\right)+0.899 z^{-0.151} .
\end{aligned}
$$

Those equations shows natural logarithmic correlation with second level polynomial or exponential coefficients, depending on the depth from the external ground level.

\section{Conclusion}

The research introduced a new simple-to-use tabulated and semi-analytical method to calculate the equivalent linear thermal transmittance of ground contact floor structures. The research and the new calculating methods may help architects and engineers in energy conscious design.

\section{References}

[1] T. Kusuda, P.R. Achenbach, ASHRAE Trans. 69, 439 (1963).

[2] S.W. Rees, Z. Zhou, H.R. Thomas, Build. Environm. 42, 1478 (2007).

[3] T. Blomberg, Ph.D. Thesis, Lund University, Sweden 1996.

[4] J.K. Latta, G.G. Boileau, Canad. Build. 19, 39 (1969).

[5] A.E. Delsante, Build. Environm. 23, 11 (1988).

[6] J. Claesson, C.E. Hagentoft, Build. Environm. 26 195 (1991).

[7] T. Kusuda, J.W. Bean, ASHRAE Trans. 90, 611 (1984).

[8] Ansys 14 User's Manual. 